\title{
Thermodynamic and kinetic parameters of biomass from black pine (PINUS NIGRA ARN.)
}

\author{
Stanislava Tasheva ${ }^{1}$, Milen Dimov ${ }^{2}$, Hafize Fidan ${ }^{3}$, Stanko Stankov ${ }^{3}$, Lazar Lazarov ${ }^{4}$, \\ Bozidar Bozadzhiev", Apostol Simitchiev ${ }^{6}$, and Albena Stoyanova ${ }^{4}$ \\ ${ }^{1}$ University of Food Technologies, Department of Heat Engineering, Bulgaria \\ ${ }^{2}$ Trakia University, Department Food Technology, Bulgaria \\ ${ }^{3}$ University of Food Technologies, Department of Tourism and Culinary Management, Bulgaria \\ ${ }^{4}$ University of Food Technologies, Department of Tobacco, Sugar, Vegetable and Essential Oil, \\ Bulgaria \\ ${ }^{5}$ University of Food Technologies, Department of Cereals, Fodder, Bread and Confectionery \\ Products, Bulgaria \\ ${ }^{6}$ University of Food Technologies, Department of Machines and Apparatuses for Food and \\ Biotechnological Industry, Bulgaria
}

\begin{abstract}
The aim of the present study was to determine the thermodynamic and kinetic parameters of biomass obtained from black pine (Pinus nigra Arn.). The biomass, consisting of twigs with needles and needles alone of black pine, was used. Ultimate analysis with the elemental composition of the biomass with respect to the main components such as carbon $(\mathrm{C})$, hydrogen $(\mathrm{H})$, nitrogen $(\mathrm{N})$, and sulfur $(\mathrm{S})$ of the biomass before and after water distillation was made. The high heating value (HHV) and low heating value (LHV), energy density and fuel value index were determined. Thermodynamic (Gibbs energy, enthalpy, and entropy) and kinetic (activation energy, the rate constant of the process, and reaction order) parameters of the biomass were calculated.
\end{abstract}

\section{Introduction}

Conventional energy sources are based on the earth's deposits of coal, peat, natural gas, and oil $[1,2]$. Residues from these natural energy sources are increasingly declining due to increased consumption of fuels and electricity $[1-4,6]$. Natural sources of energy formed nanocomposite tissue systems, which in different plant species have specific structural and functional properties [3,4]. Improving the physical and chemical characteristics of coniferous biomass increased its energy density and positively affected its industrial application.

According to the European Union's (2014) climate and energy targets, it was necessary to reduce conventional energy sources and use renewable energy sources to a greater extent by 2030 . Using renewable energy sources will reduce $\mathrm{CO}_{2}$ emissions and reduce energy

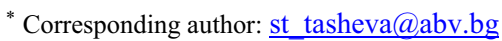


consumption by $20 \%$ (through effective saving measures), and generate $20 \%$ of primary energy from renewable energy sources [4-5].

Renewable energy sources are solar energy, geothermal heat, wind energy, and biomass (plant and animal). Plant biomass is divided into primary (natural wood, straw, crop stems, etc.) and secondary (with mechanical treatment - compaction of pellets and briquettes or with chemical treatment - vegetable oil, alcohol, paper, etc.) [1, 6-9].

Wood is a renewable energy source; it is a product of photosynthesis, i.e., carbohydrates from solar energy $[1,3,7]$. The use of wood as fuel allows saving energy sources (oil, natural gas, coal, and uranium), whose reserves are limited and whose distribution is very uneven. The main advantage of energy from wood is that it does not contribute to the greenhouse effect. The amount of carbon dioxide produced by burning wood is comparable to what is naturally produced by its decomposition. This amount of $\mathrm{CO}_{2}$ corresponds to what was absorbed by photosynthesis while the tree was growing. In this way, equilibrium is achieved $[1,3,7]$.

Based on certain kinetic parameters, the thermodynamic values of torrefaction of the isothermal biomass are calculated and analyzed.

In applied thermodynamics, it has been found that geographical location can affect the energy characteristics of plant biomass [2, 6-7]. This can be useful in determining the thermodynamic and kinetic parameters and optimize pyrolytic processes in bioreactors. Therefore, the aim of the present study was to determine the thermodynamic and kinetic parameters of the biomass obtained from black pine (Pinus nigra Arn.).

\section{Materials and methods}

\subsection{Materials}

The needles with thin twigs of black pine (P. nigra Arn.) growing in Bulgaria were used. The raw material was collected during the spring of 2020. The species has been identified in Agricultural University, Plovdiv. Before processing, the raw material was cut into particle size $1.5-2.5 \mathrm{~cm}$. It was processed by hydrodistillation into a laboratory distillation. Ash, moisture and cellulose content were determined for the studied biomass [10].

The infrared spectrum was recorded using a Nicolet iS 50 Thermo Scientific FT-IR spectrometer in the frequency region of $4000-400 \mathrm{~cm}^{-1}$, with the samples embedded in $\mathrm{KBr}$ matrixes.

\subsection{Elemental analysis}

Biomass was analyzed before and after hydrodistillation for the main components carbon $(\mathrm{C})$, hydrogen $(\mathrm{H})$, nitrogen $(\mathrm{N})$ and sulfur $(\mathrm{S})$ by elemental analysis using elemental analyzer Euro EA3000, Type (CHNSO).

\subsection{Calculations}

The upper heating value (HHV) was determined by the following equations $[1,11]$ :

$$
\mathrm{HHV}=[33.5 . \mathrm{C}+142.3 . \mathrm{H}-15.4 . \mathrm{O}-14.5 . \mathrm{N}] \cdot 10^{-2}, \mathrm{KJ} \mathrm{kg}^{-1}
$$

and

$$
\mathrm{Q}_{g}^{\mathrm{p}}=\mathrm{Q}_{\mathrm{d}}^{\mathrm{p}}+\left(\frac{9 \cdot \mathrm{H}^{\mathrm{p}}}{100}+\frac{\mathrm{W}^{\mathrm{p}}}{100}\right), \mathrm{KJ} \cdot \mathrm{kg}^{-1}
$$


where: $\mathrm{C}$ is the carbon content in the biomass, $\%$;

$\mathrm{H}$ is the hydrogen content in the biomass, $\%$;

$\mathrm{O}$ is the oxygen content in the biomass, $\%$;

$\mathrm{N}$ is the nitrogen content in the biomass, $\%$,

$\mathrm{W}$ is the moisture content in the biomass, \%;

$Q_{d}^{p}$ is the lower operating heat of combustion, $\mathrm{KJ} . \mathrm{kg}^{-1}$

$Q_{g}^{p}$ is the upper operating heat of combustion, $\mathrm{KJ} \cdot \mathrm{kg}^{-1}$

and the low heating value (LHV) and the lower operating heat of combustion $Q_{d}^{p}$ are calculated by the following equation [1-2]:

$$
\mathrm{LHV}=\mathrm{HHV}-2.447 \cdot\left(\frac{\mathrm{H} \cdot \mathrm{A}}{100}\right) \cdot 9.011, \mathrm{MJ} \cdot \mathrm{kg}^{-1}
$$

and

$$
\mathrm{Q}_{\mathrm{d}}^{\mathrm{p}}=339.39 \cdot \mathrm{C}^{\mathrm{p}}+1257 \cdot \mathrm{H}^{\mathrm{p}}+108.94\left(\mathrm{~S}^{\mathrm{p}}-\mathrm{O}^{\mathrm{p}}\right)-25 \cdot\left(9 \cdot \mathrm{H}^{\mathrm{p}}+\mathrm{W}^{\mathrm{p}}\right), \mathrm{KJ} \cdot \mathrm{kg}^{-1}
$$

The value of the fuel index is calculated, which is a parameter for classifying tree species as fuels. The value of the fuel index is calculated according to the following equation [2,1213]:

$$
F V I=\frac{H H V \cdot \rho}{A \cdot 100}, K J . \mathrm{cm}^{-3}
$$

where: HHV - upper heating value of the fuel (biomass), $\mathrm{KJ}_{\mathrm{J}} \mathrm{g}^{-1}$;

$\rho$ is the biomass density, $\mathrm{g} . \mathrm{cm}^{-3}$;

$\mathrm{A}$ is the ash content in the fuel, $\%$.

The energy density of the fuel was calculated using black pine needles with a measured bulk density of $0.243 \mathrm{~g} . \mathrm{cm}^{-3}$ and a mixture of black pine needles and branches with a measured bulk density of $0.297 \mathrm{~g} \cdot \mathrm{cm}^{-3}$, by the following equation $[2,12]$ :

$$
\mathrm{E}=L H V \cdot \rho, M J \cdot \mathrm{cm}^{-3}
$$

or

$$
\mathrm{E}_{d}=\frac{1}{3600} \cdot L H V \cdot \rho, M W h
$$

where: LHV lower heating value of fuel / biomass, KJ.g-1;

$\rho$ is the bulk density of the biomass, $\mathrm{g} . \mathrm{cm}^{-3}$;

$\frac{1}{3600}$ is the conversion factor from MJ to MWh.

The thermodynamic parameters: Gibbs energy, enthalpy, and entropy are calculated according to the equations presented in $[9,14]$ :

$$
\begin{gathered}
\Delta G=\Delta H-\Delta S \cdot T \\
\Delta G=-\ln K \cdot R \cdot T \\
\Delta H=E a-R \cdot T \\
E a=2,31 \cdot \operatorname{tg} \alpha \cdot R \cdot T
\end{gathered}
$$

where: $\Delta \mathrm{G}$ is the free energy of Gibbs, $\mathrm{KJ} \cdot \mathrm{mol}^{-1}$;

$\Delta \mathrm{H}$ is the enthalpy, $\mathrm{KJ}_{\mathrm{m}} \mathrm{mol}^{-1}$;

$\Delta \mathrm{S}$ is the entropy, $\mathrm{KJ} \cdot \mathrm{mol}^{-1} \cdot \mathrm{K}^{-1}$; 
$\mathrm{K}$ is the equilibrium constant;

$\mathrm{R}$ is the universal gas constant, $\mathrm{KJ} \cdot \mathrm{mol}^{-1} \cdot \mathrm{K}^{-1}$;

$\mathrm{T}$ is the absolute temperature, $\mathrm{K}$;

$\mathrm{Ea}$ is the activation energy, $\mathrm{KJ} \cdot \mathrm{mol}^{-1}$;

$\alpha$ is the slope determined from $\operatorname{lnK}$ vs $1 / \mathrm{T}$.

The kinetic parameters are also calculated - activation energy, process rate constant and biomass reaction order depending on moisture, ash and cellulose content, according to the Arrhenius equation from $[9,14]$ :

$$
k=A \cdot e^{-\frac{E a}{R \cdot T}, \mathrm{~s}}
$$

where: $\mathrm{k}$ is the rate constant of the reaction, $\mathrm{s}$;

$\mathrm{A}$ is the Arrhenius constant.

\section{Results and discussion}

The infrared spectra of needles and twigs with needles are presented in Table. 1. The analysis of FT-IR represented mainly strong vibrations of the components before and after treatment. The data demonstrated that all four samples had a characteristic absorption band for the $\mathrm{H}$ bond in the $\mathrm{OH}$ group (bands 3421, 3432, 3420 and $3423 \mathrm{~cm}^{-1}$ ). It is also noteworthy that the fluctuation band of the conjugated double bond $\gamma \mathrm{C}=\mathrm{C}$ for needles $\left(1618 \mathrm{~cm}^{-1}\right)$ and twigs with needles $\left(1617 \mathrm{~cm}^{-1}\right)$ before distillation was absent in the same samples after distillation. On the other hand, characteristic bands for cis - HRC $=$ CR'H (alkene) appear in the samples after distillation for needles $\left(1637 \mathrm{~cm}^{-1}\right)$ and twigs with needles $\left(1636 \mathrm{~cm}^{-1}\right)$. These changes were probably due to the high temperature $\left(100^{\circ} \mathrm{C}\right)$, which influences the regrouping of the double bonds in the studied samples.

Table 1. Infrared spectra

\begin{tabular}{|c|c|c|c|c|c|}
\hline \multicolumn{5}{|c|}{ Characteristic stripes $\left(\mathrm{cm}^{-1}\right)$} & \multirow{2}{*}{ Group type } \\
\hline \multicolumn{2}{|c|}{ Needles } & \multicolumn{2}{|c|}{$\begin{array}{l}\text { Twigs with } \\
\text { needles }\end{array}$} & \multirow[t]{2}{*}{$\begin{array}{l}\text { Data from } \\
\text { the directory }\end{array}$} & \\
\hline before & After & before & after & & \\
\hline 3421 & 3432 & 3420 & 3423 & $3590-3420$ & $\gamma \mathrm{OH}$ intramolecular $\mathrm{H}-$ bond \\
\hline 2922 & 2924 & 2922 & 2925 & $2940-2915$ & $\gamma_{\text {as }}-\mathrm{CH}_{2}-$ \\
\hline- & 2361 & 2852 & 2362 & $3110-2362$ & $\gamma_{\mathrm{s}}-\mathrm{CH}_{2}-$ \\
\hline 1735 & - & 1732 & 1735 & $1740-1720$ & $\begin{array}{l}\mathrm{R}-\mathrm{CHO} \gamma \mathrm{C}=\mathrm{O} \text { characteristic band for } \\
\text { aldehyde carbonyl group }\end{array}$ \\
\hline- & - & 1694 & - & $1740-1650$ & valence fluctuation of the $\gamma \mathrm{C}=\mathrm{O}$ group \\
\hline- & 1637 & - & 1636 & $1665-1635$ & characteristic band for cis $-\mathrm{HRC}=\mathrm{CR}^{\prime} \mathrm{H}$ \\
\hline 1618 & - & 1617 & - & $1625-1600$ & $\begin{array}{l}\text { band of valence oscillation of the conjugated } \\
\text { double bond } \gamma \mathrm{C}=\mathrm{C} \text {, flat with high intensity }\end{array}$ \\
\hline
\end{tabular}




\begin{tabular}{|c|c|c|c|c|c|}
\hline 1514 & - & 1514 & 1517 & $1525-1475$ & $\begin{array}{c}\text { a band with variable intensity characteristic } \\
\text { of an aromatic nucleus, oscillations for } \gamma \\
\mathrm{C}=\mathrm{C}\end{array}$ \\
\hline 1450 & - & 1455 & 1458 & $1480-1450$ & \begin{tabular}{c} 
linear $-\mathrm{CH}_{2}-$ groups \\
\hline 1377
\end{tabular} 1384 \\
\hline 1264 & - & 1384 & 1375 & $1385-1370$ & $\begin{array}{c}\text { stripes corresponding to a structural fragment } \\
\text { of type } \mathrm{C}\left(\mathrm{CH}_{3}\right)_{2}\end{array}$ \\
\hline- & - & 1158 & - & $1175-1125$ & $\begin{array}{c}\text { monosubstituted 1,3 C-H in the aromatic } \\
\text { nucleus }\end{array}$ \\
\hline 1035 & 1030 & 1035 & 1031 & $1070-1000$ & $\begin{array}{c}\text { planar deformation oscillations 1,2,4 } \\
\text { substituted C-H in aromatic nucleus }\end{array}$ \\
\hline
\end{tabular}

The data of the biomass content (before and after treatment) are presented in Fig. 1 and Fig. 2, as the biomass composition is recalculated to $100 \%$ of the total amount of raw material used.

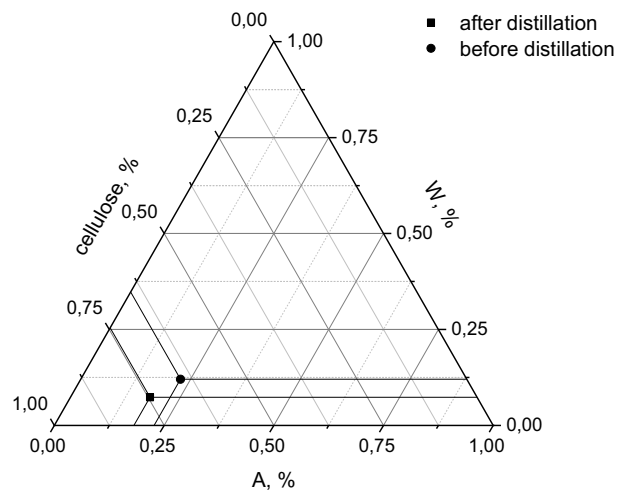

Fig. 1. Ash, moisture and cellulose content in black pine needles

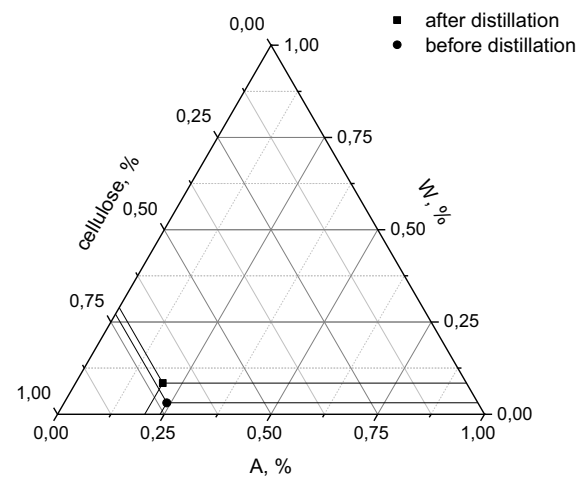

Fig 2. Content of ash, moisture and cellulose in needles and twigs of black pine 
Table 2 shows the defined elemental composition of black pine biomass - needles and twigs with needles, before and after distillation.

Table 2. Elemental composition of black pine biomass

\begin{tabular}{|c|c|c|c|c|c|}
\hline Sample & $\mathbf{C}$ & $\mathbf{H}$ & $\mathbf{N}$ & $\mathbf{S}$ & $\mathbf{O}$ \\
\hline Needles before distillation & $51.44 \pm 0.32$ & $7.28 \pm 0.24$ & $1.55 \pm 0.24$ & $0.10 \pm 0.02$ & $27.17 \pm 0.72$ \\
\hline $\begin{array}{c}\text { Needles after distillation } \\
\text { Twigs with needles before } \\
\text { distillation }\end{array}$ & $50.53 \pm 0.30$ & $7.58 \pm 0.25$ & $1.82 \pm 0.29$ & $0.10 \pm 0.02$ & $30.01 \pm 0.72$ \\
\hline $\begin{array}{c}\text { Twigs with needles after } \\
\text { distillation }\end{array}$ & $52.76 \pm 0.38$ & $7.48 \pm 0.10$ & $1.75 \pm 0.20$ & $<0.10$ & $27.29 \pm 071$ \\
\hline
\end{tabular}

$\mathrm{C}$ - carbon content, $\% ; \mathrm{H}$ - hydrogen content, $\% ; \mathrm{N}$ - nitrogen content, $\% ; \mathrm{S}$ - sulfur content, $\% ; \mathrm{O}$ - oxygen content, $\%$, The oxygen content is calculated based on the elemental analysis of the biomass, as the ash and moisture contents are predicted according to [11-12,15-17].

The oxygen content was calculated according to the presented studies for the elemental composition (in Table 2) and the basis of the elemental composition given up to $100 \%$ in [1112,15-17], taking into account the ash and moisture content. The obtained values of the elemental composition of biomass for black pine are approximately close to the composition of pinewood and sawdust reported by other authors $[8,18]$, stem, branches, needles, and tips of pine [6, 9-10]. Biomass contains cellulose, lignin and hemicellulose in different proportions depending on the type of plant parts (branches, tops, wood) and the plant age, as described in $[15,19]$. The difference in the values of the tested components could be explained by the influence of the high temperature during distillation $\left(100{ }^{\circ} \mathrm{C}\right)$, associated with the course of different chemical processes between the different functional groups of the compounds.

The energy characteristics of black pine biomass for black pine needles and twigs were calculated before and after biomass distillation (Table 3 ).

Table 3. Energy characteristics of black pine biomass

\begin{tabular}{|c|c|c|c|c|c|c|c|}
\hline Sample & $\begin{array}{c}\text { HHV, } \\
\text { MJ.kg-1 }^{-1}\end{array}$ & $\begin{array}{c}\text { LHV, } \\
\text { MJ.kg- } \\
1\end{array}$ & $\begin{array}{c}Q_{g}^{p}, \\
\text { MJ.kg }^{-1}\end{array}$ & $\begin{array}{c}Q_{d}^{p}, \\
\text { MJ.kg-1 }\end{array}$ & $\begin{array}{c}\text { E, } \\
\text { MJ.cm-3 }\end{array}$ & $\begin{array}{c}\text { FVI.10 }{ }^{-3}, \\
\text { kJ.cm }^{-3}\end{array}$ & $\begin{array}{r}\mathbf{E}_{\mathrm{d}}, \\
\mathbf{k W h}\end{array}$ \\
\hline $\begin{array}{l}\text { Needles before } \\
\text { distillation }\end{array}$ & 23.18 & 16.26 & 23.66 & 21.82 & 3.95 & 13.07 & 1.10 \\
\hline $\begin{array}{c}\text { Needles after } \\
\text { distillation }\end{array}$ & 22.82 & 18.04 & 23.42 & 21.54 & 4.38 & 19.39 & 1.22 \\
\hline $\begin{array}{l}\text { Twigs with needles } \\
\text { before distillation }\end{array}$ & 25.56 & 8.12 & 25.60 & 23.68 & 2.41 & 6.02 & 0.67 \\
\hline $\begin{array}{l}\text { Twigs with needles } \\
\text { after distillation }\end{array}$ & 23.86 & 18.71 & 24.35 & 22.48 & 5.56 & 18.58 & 1.54 \\
\hline
\end{tabular}

HHV - upper heating value, MJ.kg-1 LHV - low heating value, MJ.kg-1 $Q_{g}^{p}$ - upper operating heat of combustion, MJ.kg ${ }^{-1} ; Q_{d}^{p}$ - lower operating heat of combustion, MJ.kg-1 $; \mathrm{E}$ - energy density, $\mathrm{MJ} . \mathrm{cm}^{-3}$; FVI - value of fuel index, $\mathrm{kJ} . \mathrm{cm}^{-3} ; \mathrm{E}_{\mathrm{d}}$ - energy density, kWh.

The data for the energy characteristics of the biomass from needles and twigs with black pine needles reported in a previous study were in the range of $16.75-16.88 \mathrm{~kJ}^{-\mathrm{kg}^{-1}}$ [10]. Many authors have studied the energy values of different types of pine and different parts of pine wood (needles, branches, bark, tree part, and cones) [2, 12-14, 16-17, 20]. The values for the 
upper heat of combustion were in agreement with those reported in this study, regardless of the equation used for its calculation. There is a difference in calculating the lower heat of combustion, depending on the equation used.

The energy density of wood is a characteristic that gives an indication of the biomass' storage and transport. According to [15], high destiny and high LHV values have more energy per unit volume. Pelletizing significantly increases the energy density, which in turn reduces storage needs. The energy density with the other characteristics of the wood and the installation, in which it will be processes, will be influenced mainly by the equipment and its compaction, which therefore will determine the produced pellets' bulk density [2].

The fuel index is a parameter for assessing the quality of wood biomass. The increasing of the fuel index leads to the better biomass's fuel quality [15]. The fuel index value is regarded as a standard parameter for identifying suitable tree species for firewood production [15, 21-22].

According to [9], as the ash content in the biomass increases, the value of the fuel index and its energy density decreases. Energy density is an indicator used in the storage and transport of biomass [15].

Table 4 presents the thermodynamic parameters of black pine biomass for needles and twigs after a distillation process.

Table 4. Thermodynamic parameters of black pine biomass

\begin{tabular}{|c|c|c|c|c|c|c|c|}
\hline \multirow{2}{*}{ Sample } & \multicolumn{2}{|c|}{ Content, \% } & $\mathrm{t}, \mathrm{s}$ & $\begin{array}{c}\Delta \mathrm{G}, \\
\mathrm{kJ} \cdot \mathrm{mol}^{-1}\end{array}$ & $\begin{array}{c}\Delta \mathrm{S}, \\
\mathrm{kJ} \cdot \mathrm{mol}^{-1} \cdot \mathrm{K}^{-1}\end{array}$ & $\begin{array}{c}\Delta \mathrm{H}, \\
\mathrm{kJ}_{\mathrm{m}} \mathrm{mol}^{-1}\end{array}$ & $\mathrm{k} \cdot 10^{3}, \mathrm{~s}$ \\
\hline \multirow{2}{*}{$\begin{array}{c}\text { Black pine } \\
\text { needles }\end{array}$} & Moisture & 7.17 & 10800 & -5929.57 & -35.04 & 7144.76 & 0.29 \\
\cline { 2 - 8 } & Ash & 2.86 & 10800 & -2107.31 & -24.80 & 7144.76 & 0.40 \\
\cline { 2 - 8 } & Cellulose & 29.24 & 10800 & -5014.39 & -32.59 & 7144.76 & 1.61 \\
\cline { 2 - 8 } \\
$\begin{array}{c}\text { Black pine } \\
\text { twigs and } \\
\text { needles }\end{array}$ & Ash & 3.12 & 10800 & 2590.04 & -12.21 & 7144.76 & 2.00 \\
\cline { 2 - 8 } & Cellulose & 26.16 & 10800 & -8279.01 & -41.33 & 7144.76 & 0.50 \\
\hline
\end{tabular}

$\mathrm{t}$ - duration of process, $\mathrm{s} ; \Delta \mathrm{G}$ - the free energy of Gibbs, $\mathrm{kJ} \cdot \mathrm{mol}^{-1} ; \Delta \mathrm{S}$ - the entropy, $\mathrm{kJ} \cdot \mathrm{mol}^{-1} \cdot \mathrm{K}^{-1} ; \Delta \mathrm{H}$ the enthalpy, $\mathrm{kJ} . \mathrm{mol}^{-1} ; \mathrm{k}$ - the rate constant, s.

From the representation of values of thermodynamic parameters, it could be concluded that the distillation process was stable and proceeded irreversibly and spontaneously. The negative values of entropy confirmed that the process is irreversible and spontaneous. The enthalpy obtained in distillation from biomass of needles and twigs of black pine was equal in value to the activating energy with the opposite sign. The positive values obtained for enthalpy indicated an endothermic process, i.e., in order to carry out the process, introduction of heat was required. The value obtained for the activating energy is $\mathrm{Ea}=-7144.76 \mathrm{~kJ} . \mathrm{mol}^{-1}$, which means that it is necessary to introduce heat during the distillation process in order to carry out this process. The order of the reaction was determined by the differential method; the reaction was of zero-order, the values of the calculated rate constants were given in the Table 4. 


\section{Conclusion}

The ash, moisture, and cellulose contents of black pine samples (needles and branches with needles) were determined in this study. Elemental analysis of the combustible elements has been made. The upper and lower combustion thickness, fuel index, and energy density of the considered samples were calculated. Thermodynamic parameters (gypsum energy, enthalpy, and entropy energy) and kinetic parameters (activating energy, rate constant, and reaction order) were also calculated. From the representation of values of thermodynamic parameters, it could be concluded that the distillation process was stable and proceeded irreversibly and spontaneously. The negative values of entropy confirmed that the process is irreversible and spontaneous. The enthalpy obtained in distillation from biomass of needles and twigs of black pine was equal in value to the activating energy with the opposite sign. The positive values obtained for enthalpy indicated an endothermic process, i.e., in order to carry out the process, introduction of heat was required. The value obtained for the activating energy is Ea = $7144.76 \mathrm{~kJ} \mathrm{~mol}^{-1}$, which means that it is necessary to introduce heat during the distillation process in order to carry out this process. The order of the reaction was determined by the differential method; the reaction was of zero-order.

The authors acknowledge the support by the National Science Fund of Bulgaria, project No KP-06H36/14.

\section{References}

1. G. Valtchev, Fuel technics and technologies, (EDP UFT-Plovdiv, second edition, (2011).

2. T. Miranda, I. Montero, F. Sepulveda, J. Arranz, C. Rojas, S. Nogales- Materials, 8, 1413, (2015).

3. G. Boyadzhieva, B. Baykov, B. Angelov, Ecologization, NBU, 40, (2012).

4. 2030 Climate and Energy Goals for A Competitive, Secure And Low-Carbon Eu Economy. European Commission-Ip/14/54, (2014).

5. Directive 2009/28/Ec of The European Parliament And Of The Council of 23 April 2009 On The Promotion of The Use Of Energy From Renewable Sources and Amending And Subsequently Repealing Directives 2001/77/Ec And 2003/30/Ec. Official Journal of The European Union: Brussels, Belgium, (2009).

6. S. Soltani, S. M. S. Mahmoudi, M. Yari, M. A. Rosen, Appl. Therm. Eng., 59, 60, (2013).

7. P. McKendry, Bioresource Technology, 83, 37, (2002).

8. O. Olatunji, S. A. Akinlabi, M. P. Mashinini, S. O. Fatoba, O. O. Ajay, IOP Conf. Series: Materials Science and Engineering 423, 012175, (2018). doi:10.1088/1757$899 x / 423 / 1 / 012175$

9. Colomba Di Blasi, PECS, 34, 47, (2008).

10. H. Fidan, S. Stankov, N. Petkova, B. Bozadziev, M. Dimov, L. Lazarov, A. Simitchiev, A. Stoyanova, Proceedings of $9^{\text {th }}$ Europen Confonference on Renewable Energy System, 408, (2021). www.ecres.net

11. R. Moya, C. Tenorio, Biomass \& Energy, 56, 14, (2013).

12. Y. Sing, P. Mahanta, U. Bora, Renewable Energy, 103, 490, (2017).

13. B.P. Bhatt, J.M.S. Tomar, K.M. Bujarbaruah, Renewable Energy, 29, 1401, (2004).

14. T. Sen, S. Afroze, H. Ang, Water Air Soil Pollut, doi: 10.1007/s11270-010-0663-y. 
15. H. Viana, A. Rodrigues, R. Godina, J. Matias, L. Nunes, Sustainability, 10, 2877, (2018).

16. K. Motghare, A. Rathod, K. Wasewar, N. Labhsetwar, Waste Management, 47, 40, (2016).

17. V. Petkov, E. Mihailov, N. Kazakova, Journal of Chemical Technology and Metallurgy, 49(1), 94, (2014).

18. O. Olatunji, S. Akinlabi, O. Ajayi, P. Mashinini, M. Nkosinath, IOP Conf. Series: Materials Science and Engineering, 413, 012054, (2018). doi:10.1088/1757$899 x / 413 / 1 / 012054$

19. M. Brebu, C. Vasile, Cellulose Chemistry and Technology Cellulose Chem. Technol., 44 (9), 353, (2010).

20. B.P. Bhatt, J.M.S. Tomar, Biomass and Bioenergy, 23, 257, (2002).

21. S.B.Meetei, E.J.Singh, A.K. Das, J. Environ. Biol., 36, 1007, (2015).

22. V.Saravanan, K.T.Parthiban, P.Kumar, P.V.Anbu, P.G. Pandian, Res. J. Agric. For. Sci., 1, 8, (2013). 